\title{
Efficacy of DA-9701 (Motilitone) in Functional Dyspepsia Compared to Pantoprazole: A Multicenter, Randomized, Double-blind, Non-inferiority Study
}

\begin{abstract}
Hye-Kyung Jung, ${ }_{1}^{1}$ Kwang Jae Lee, ${ }^{2 *}$ Myung-Gyu Choi, ${ }^{3}$ Hyojin Park, ${ }^{4}$ Joon Seong Lee, ${ }^{5}$ Poong-Lyul Rhee, ${ }^{6}$ Nayoung Kim, ${ }^{7}$ Kyung Sik Park, ${ }^{8}$ Suck Chei Choi, ${ }^{9}$ Oh Young Lee, ${ }^{10}$ Kyu Chan Huh, ${ }^{11}$ Geun Am Song, ${ }^{12}$ Su Jin Hong, ${ }^{5}$ Chong Il Sohn, ${ }^{13}$ Hwoon-Yong Jung, ${ }^{14}$ Yong Chan Lee, Jong Sun Rew, ${ }^{15}$ Sam Ryong Jee, ${ }^{16}$ and Joong Goo Kwon ${ }^{17}$

${ }^{1}$ Department of Internal Medicine, Ewha Womans University School of Medicine, Seoul, Korea; ${ }^{2}$ Department of Gastroenterology, Ajou University School of Medicine, Suwon, Gyeonggi-do, Korea; ${ }^{3}$ Department of Internal Medicine, Catholic University College of Medicine, Seoul, Korea; ${ }^{4}$ Department of Internal Medicine, Yonsei University College of Medicine, Seoul, Korea; ${ }^{5}$ Department of Internal Medicine, Soonchunhyang University College, Seoul, Korea; ${ }^{6}$ Department of Internal Medicine, Samsung Medical Center, Sungkyunkwan University School of Medicine, Seoul, Korea; ${ }^{7}$ Department of Internal Medicine, Seoul National University Bundang Hospital, Seongnam, Gyeonggi-do, Korea; ${ }^{8}$ Department of Internal Medicine, Keimyung University College of Medicine, Daegu, Korea; ${ }^{9}$ Department of Internal Medicine, Wonkwang University College of Medicine, Iksan, Jeollabuk-do, Korea; ${ }^{10}$ Department of Internal Medicine, Hanyang University College of Medicine, Seoul, Korea; ${ }^{11}$ Department of Internal Medicine, Konyang University College of Medicine, Daejeon, Korea; ${ }^{12}$ Department of Internal Medicine, Pusan National University College of Medicine, Busan, Korea; ${ }^{13}$ Department of Internal Medicine, Kangbuk Samsung Medical Center, Sungkyunkwan University School of Medicine, Seoul, Korea; ${ }^{14}$ Department of Internal Medicine, Asan Medical Center, University of Ulsan College of Medicine, Seoul, Korea; ${ }^{15}$ Chonnam National University Medical School, Gwangju, Korea; ${ }^{16}$ Department of Internal Medicine, Inje University College of Medicine, Busan, Korea; and ${ }^{17}$ Department of Internal Medicine, Catholic University of Daegu, School of Medicine, Daegu, Korea
\end{abstract}

\section{Background/Aims}

The effect of proton pump inhibitors (PPI) in Asian functional dyspepsia (FD) patients has not been well established as in Western countries. DA-9701, a novel prokinetic agent, stimulates gastric emptying and modulates visceral hypersensitivity in vivo and in human studies. This study was conducted to compare the efficacy of DA-9701 with a conventional PPI in mono or combination therapy in patients with FD.

\section{Methods}

In this double-blind, randomized, non-inferiority trial, 389 patients diagnosed with FD using Rome III criteria were allocated among 3 groups: 30-mg DA-9701 t.i.d (means 3 times a day), 40-mg pantoprazole, and 30-mg DA-9701 t.i.d + 40-mg pantoprazole. The primary efficacy end-point was a global assessment of the patient binary response or response on a 5-Likert scale after 4 weeks.

\section{Results}

The global symptomatic improvement was $60.5 \%$ in the DA-9701 group, $65.6 \%$ in the pantoprazole group, and $63.5 \%$ in the DA9701 + pantoprazole group using a 5-Likert scale at week 4 with no significant difference among 3 groups $(P=0.685)$. Symptom improvement measured by binary outcome was significantly achieved in each of the 3 groups, but not different among groups. Patients in all treatment groups reported significant improvement in the response rate and symptoms according to FD subtypes and dyspepsia-related quality of life $(P<0.001)$, but there were no significant differences among the 3 groups.

\section{Received: October 13, 2015 Revised: December 28, 2015 Accepted: January 17, 2016}

(a) This is an Open Access article distributed under the terms of the Creative Commons Attribution Non-Commercial License (http://creativecommons. org/licenses/by-nc/4.0) which permits unrestricted non-commercial use, distribution, and reproduction in any medium, provided the original work is properly cited.

*Correspondence: Kwang Jae Lee, MD Department of Gastroenterology, Ajou University Hospital, Ajou University School of Medicine, 164 Worldcup-ro, Yeongtong-gu, Suwon, Gyeonggi-do 16499, Korea Tel: +82-31-219-5102, Fax: +82-31-219-5999, E-mail: kjleemd@hotmail.com 


\title{
Conclusions
}

DA-9701 improves global and individual symptoms and increases dyspepsia-specific quality of life in patients with FD. The efficacy of DA-9701 monotherapy is comparable with pantoprazole and there is no additive effect with combination of DA-9701 and pantoprazole in patients with FD.

\section{(J Neurogastroenterol Motil 2016;22:254-263)}

\author{
Key Words \\ DA-9701 (Motilitone); Dyspepsia; Proton pump inhibitor
}

\section{Introduction}

Dyspepsia is a common disease that accounts for $\sim 5 \%$ of patients who visit their primary health care provider and functional dyspepsia (FD) accounts for $60-80 \%$ of all patients with dyspepsia. ${ }^{1,2}$ Pathophysiological mechanisms of FD may be multifactorial and remain to be fully elucidated, although widely recognized mechanisms are gastroduodenal dysmotility, gastroduodenal acid exposure, visceral hypersensitivity, autonomic/central nervous system dysfunction, Helicobacter pylori infection, and psychosomatic factors. ${ }^{3,4}$ Standard management of FD has not yet been established and satisfactory pharmacotherapy is also unavailable.

Anti-secretory drugs, such as proton pump inhibitors (PPIs), have been evaluated extensively for FD therapy despite little evidence that acid is involved in the development of FD. Cochrane meta-analysis revealed that the average dyspepsia cure rate (no or minimal symptoms) to PPI therapy was $34 \%$, which was significantly higher compared to $25 \%$ in the placebo. Based on this result, 10 participants (95\% confidence interval [CI], 7-33) would need treatment with PPI to cure one case of FD that would not have been cured by placebo. ${ }^{5}$ This meta-analysis included the studies from 1998 to 2006, and the placebo effect in the analysis of PPI efficacy was relatively lower than that in the analysis of prokinetics $(47 \%)$ or histamine 2 receptor antagonist $(40 \%)^{5}{ }^{5}$

PPIs are well tolerated, and the incidence of adverse effects is relatively low with short-term use. However, there are several recent reports on the possible adverse events related to the long-term use of PPIs, such as community acquired pneumonia, Clostridium difficile infection, hip fracture, or hypomagnesemia. ${ }^{6}$ Therefore, the development of safer and more effective drug for FD is needed.

Prokinetic drugs, especially cisapride, are the most effective therapy for dyspepsia. The Cochrane review showed that the response rate by dichotomous global dyspepsia outcome was $57 \%$ compared to $47 \%$ in the placebo arm with 6, the number that would need treatment to be effective for dyspepsia. ${ }^{5}$ However, most studies in this meta-analysis were based on cisapride drug trials with significant heterogeneity. Furthermore, cisapride has been taken off the market due to serious adverse cardiac events, and prokinetic agents such as metoclopramide, erythromycin, and tegaserod have little or no established efficacy and often, substantial side effects. In a recent open-label, randomized controlled trial with prokinetics compared to PPI in Asia, significant symptom relief was achieved in $50.6 \%$ of the PPI group and $47.9 \%$ of the prokinetics groups, and therapeutic responses between the 2 groups were not different. ${ }^{8}$

DA-9701 (Motilitone) is a newly formulated prokinetic agent obtained from vegetal extracts of Pharbitidis semen and Corydalis tuber, used as traditional treatments for their analgesic and antiulcer effects. ${ }^{9}$ In animal studies, DA-9701 improved the symptoms of FD by accelerating gastric emptying, promoting gastric accommodation, and modulation of visceral hypersensitivity through the antagonistic action at 5-hydroxytryptamine $(\mathrm{HT})_{3}$ or dopamine $(\mathrm{D})_{2}$ receptors, or agonistic action at the $5-\mathrm{HT}_{4}$ receptor. ${ }^{10-12}$

The aim of this study was (1) to investigate the efficacy of DA9701 on improvement of FD symptoms compared with PPIs and (2) to evaluate the additive effect of DA-9701 over PPI treatment alone. This study was conducted with a multicenter, double-blind, randomized, parallel-comparative phase IV study to compare the efficacy and safety of DA-9701 monotherapy with mono or combination therapy of pantoprazole.

\section{Materials and Methods}

\section{Study Design and Intervention}

This clinical trial was conducted at 20 tertiary hospitals in Korea. The study protocol was approved by the Ethical Review Committee at each institute, and written informed consent was obtained from all participants. This trial was registered with Clinical-Trials. gov (number NCT01817465). 


\section{Patients}

Male and female patients $>20$ years of age who had FD were enrolled. FD was defined by Rome III criteria as patients with one or more symptoms of epigastric pain or soreness, postprandial fullness, or early satiation for the past 3 months with symptom onset at least 6 months prior to diagnosis; no evidence of structural disease that was likely to explain symptoms; no organic lesion detected by endoscopic examination.

Exclusion criteria were patients who had taken other investigational products within 1 month of the study, previous major abdominal surgery (except appendectomy and hysterectomy), patients who had an active or healing stage peptic ulcer in the last 6 months, reflux esophagitis of Los Angeles classification A-D grades, histories of stomach cancer, esophageal cancer, pancreatitis, pancreatic cancer, inflammatory bowel disease, or biliary tract disease except asymptomatic cholelithiasis, patients who had typical symptoms of gastroesophageal reflux symptoms at least once a week, or irritable bowel syndrome. Further exclusion criteria can be found at ClinicalTrials.gov (number NCT01817465).

\section{Randomization and Investigation}

Randomization of this study was conducted the day before the initiation of clinical trial using the PLAN procedure contained in SAS ver. 9.2 (SAS Institute, Cary, NC, USA). A block randomization method was applied to each institution and the seed assigned on the basis of when date randomization was conducted. Concealed allocation was assured using an encrypted code by Clinical Research Organization (C\&R Research Inc, Seoul, Korea). Eligible patients were assigned to 3 groups: $30-\mathrm{mg}$ DA-9701 ti.d (means 3 times a day), 40-mg pantoprazole, and 30-mg DA-9701 ti.i.d + 40mg pantoprazole. Three groups were allocated on the basis of the probability of 1:1:1. The appearance, packing, and labeling of the DA-9701, pantoprazole and each placebo tablet were identical to maintain blinding to investigators and patients. One tablet of pantoprazole or pantoprazole placebo was taken daily before breakfast, and 1 tablet of DA-9701 or DA-9701 placebo was taken 3 times per day before a meal for 4 weeks. Drug compliance was assessed by counting the returned unused tablets at each clinic visit and an intake of over $80 \%$ of the prescribed study medication was acceptable.

During the study period, other gastric motility regulators, histamine $\mathrm{H}_{2}$ receptor antagonists, other PPIs, non-steroidal antiinflammatory drugs, anti-cholinergics, erythromycin, adrenocortical hormones, anti-depressants, or other investigational drugs were prohibited, except low-dose aspirin for cardiac disease. H. pylori infection was detected by rapid urease test or urea breath test.

\section{Efficacy Assessment}

The primary efficacy end-point was a global symptom assessment. Subjects evaluated the drug effects after 4 weeks of administration using a 5-Likert scale (symptom-free, markedly improved, moderately improved, slightly improved, not improved or deteriorated) and binary outcome (yes/no response). Treatment success was defined as a response of "yes" on the binary outcome survey or "symptom free, or markedly improved symptoms or moderately improved" on the 5-Likert scale.

Secondary efficacy end-points were defined by the response rates, the difference of each score and total score of FD symptoms, the difference in dyspepsia-specific quality of life (QOL) outcomes, the symptomatic relief according to the subtypes of $\mathrm{FD}$, ie, epigastric pain syndrome (EPS) and postprandial distress syndrome (PDS). A response was defined as $>50 \%$ reduction in the total score calculated by multiplying frequency by the intensity of 4 main symptoms based on the participant's diary entries. The total score was defined as the sum of the average of each FD symptom score. Nepean dyspepsia index Korean version was used to measure the dyspepsia-specific QOL. ${ }^{13}$

\section{Safety Assessment and Determination of Sample Size}

Treatment-emergent events and adverse drug reactions were reported at each institution every 2 weeks after randomization for 4 weeks. The safety set was a group of subjects who took the investigational product at least once after randomization and underwent safety-related follow-up. All analyses, including evaluation of demographic information, efficacy, and safety, were carried out a two-tailed test with the significance set at $P<0.05$ using the SAS software (Enterprise Guide 4.3; SAS Institute, Cary, NC, USA). Normality tests were conducted on all continuous variables and results compared using a paired $t$ test, analysis of variance, Wilcoxon signed rank test, or Kruskal-Wallis test depending on whether the data were normally distributed. Categorical data variables were analyzed using Chi-square test or Fisher's exact test.

For estimating the necessary number of subjects, a general evaluation improvement rate was assumed to be $60 \%$ in the DA9701 monotherapy group, $50 \%$ in the pantoprazole monotherapy group, and $70 \%$ in the DA-9701 + pantoprazole combination group, based on a previous study. ${ }^{9}$ The number of subjects was calculated on the assumption of a $5 \%$ significance level ( $\alpha$, two-sided), $80 \%$ test power $(1-\beta)$, and assigned the same number of subjects 
to 3 groups. This calculation determined that 347 subjects were needed for analysis. Assuming a $10 \%$ withdrawal rate, a total of 387 subjects was needed for the study, with 129 subjects in each group.

\section{Results}

\section{Study Population}

This study was conducted from August 2012 to March 2014. A total of 389 participants were randomized after screening 433 subjects and excluding 44 subjects. There were 131 patients in the DA-9701 group, 131 patients in the pantoprazole group, and 127 patients in the DA-9701 + pantoprazole group enrolled in the study. Finally, 115 subjects $(87.8 \%)$ in the DA-9701 group, 109 subjects $(83.2 \%)$ in the pantoprazole group, and 108 subjects $(85.0 \%)$ in the DA-9701 + pantoprazole group completed the study (Fig. 1).

\section{Demographic and Baseline Characteristics Before Administration}

There were no statistical differences in gender, age or body mass index among the administration groups. The ratio of positive H. pylori infection was $33.3 \%$ in the DA-9701 group, $35.4 \%$ in the pantoprazole group and $37.8 \%$ in the DA-9701 + pantoprazole group. There were no differences in demographic information and baseline characteristics among the 3 groups (Table 1). Postprandial fullness was the most common presenting symptom and the proportion of FD subtypes by Rome III criteria was not different among the groups.

\section{Global Symptomatic Relief}

The global symptom improvement rate at week 4 using the 5 -Likert scale as the primary endpoint was $60.5 \%$ in the DA-9701 group, $65.6 \%$ in the pantoprazole group, and $63.5 \%$ in the DA$9701+$ pantoprazole group (Table 2). However, there was no significant difference among the 3 groups $(P=0.685)$. The global

\begin{tabular}{|c|c|c|}
\hline & 433 screening & \\
\hline & 44 screening failure & \\
\hline \multicolumn{3}{|c|}{389 randomization } \\
\hline 131 DA-9701 & 131 pantoprazole & 127 DA-9701 + pantoprazole \\
\hline $\begin{array}{l}2 \text { safety set failed } \\
1 \text { not-treated } \\
1 \text { lost to F/U } \\
\text { (2 including drop-out) }\end{array}$ & $\begin{array}{l}0 \text { safety set failed } \\
0 \text { not-treated } \\
0 \text { lost to } \mathrm{F} / \mathrm{U} \\
\text { ( } 0 \text { including drop-out) }\end{array}$ & $\begin{array}{l}1 \text { safety set failed } \\
1 \text { not-treated } \\
0 \text { lost to } \mathrm{F} / \mathrm{U} \\
\text { (1 including drop-out) }\end{array}$ \\
\hline \multicolumn{3}{|c|}{386 safety set } \\
\hline 129 DA-9701 & 131 pantoprazole & 126 DA-9701 + pantoprazole \\
\hline $\begin{array}{l}14 \text { PP set failed } \\
4 \text { dropout } \\
2 \text { met the exclusion } \\
\text { criteria } \\
7 \text { deviation of } \\
\text { standard for drug } \\
\text { compliance } \\
1 \text { deviation of } \\
\text { randomization } \\
0 \text { taking prohibited } \\
\text { drugs } \\
\end{array}$ & \begin{tabular}{|l}
22 PP set failed \\
5 drop-out \\
0 met the exclusion \\
criteria \\
12 deviation of \\
standard for drug \\
compliance \\
1 deviation of \\
randomization \\
4 taking prohibited \\
drugs \\
\end{tabular} & \begin{tabular}{|l}
18 PP set failed \\
4 drop-out \\
1 met the exclusion \\
criteria \\
10 deviation of \\
standard for drug \\
compliance \\
0 deviation of \\
randomization \\
3 taking prohibited \\
drugs \\
\end{tabular} \\
\hline \multicolumn{3}{|c|}{332 PP set } \\
\hline 115 DA-9701 & 109 pantoprazole & 108 DA-9701 + pantoprazole \\
\hline
\end{tabular}

Figure 1. Inclusion and exclusion flow chart for enrollment of study participants. The causes of per protocol (PP) set failure are as follows: for DA-9701 group, dropout $(\mathrm{n}=4)$, exclusion criteria $(n=2)$, deviation of standard for drug compliance $(\mathrm{n}=7)$, and deviation of randomization $(\mathrm{n}=1)$; for pantoprazole group, dropout $(\mathrm{n}=5)$, deviation of standard for drug compliance $(\mathrm{n}=$ 12), deviation of randomization $(\mathrm{n}=1)$, and taking prohibited drugs $(n=4)$; for DA-9701 + pantoprazole group, dropout $(n=4)$, exclusion criteria $(n=$ 1), deviation of standard for drug compliance $(\mathrm{n}=10)$, and taking prohibited drugs $(\mathrm{n}=3) . \mathrm{F} / \mathrm{U}$, follow-up. 
Table 1. Demographic and Baseline Characteristics of Subjects

\begin{tabular}{|c|c|c|c|c|c|}
\hline & $\begin{array}{l}\text { DA-9701 } \\
(\mathrm{n}=131)\end{array}$ & $\begin{array}{c}\text { Pantoprazole } \\
(\mathrm{n}=131)\end{array}$ & $\begin{array}{c}\text { DA-9701 + pantoprazole } \\
(\mathrm{n}=127)\end{array}$ & $\begin{array}{c}\text { Total } \\
(\mathrm{n}=389)\end{array}$ & $P$ \\
\hline Age (mean $\pm \mathrm{SD}, \mathrm{yr})$ & $43.3 \pm 13.9$ & $43.4 \pm 13.7$ & $43.7 \pm 14.2$ & $43.5 \pm 13.9$ & $0.992^{\mathrm{a}}$ \\
\hline Female gender (n $[\%])$ & $96(73.3)$ & $102(77.9)$ & $86(67.7)$ & $284(73.0)$ & $0.185^{\mathrm{b}}$ \\
\hline Body mass index $\left(\right.$ mean $\left.\pm \mathrm{SD}, \mathrm{kg} / \mathrm{m}^{2}\right)$ & $22.5 \pm 3.2$ & $21.9 \pm 3.0$ & $22.6 \pm 3.2$ & $22.3 \pm 3.2$ & $0.171^{\mathrm{a}}$ \\
\hline Current smokers (n $[\%]$ ) & $12(9.2)$ & $8(6.1)$ & $8(6.3)$ & $28(7.2)$ & $0.580^{\mathrm{b}}$ \\
\hline Alcohol users (n [\%]) & $39(29.8)$ & $38(29.0)$ & $38(29.9)$ & $115(29.6)$ & $0.985^{\mathrm{b}}$ \\
\hline Helicobacter pylori-positive (n [\%]) & $43(33.3)$ & $46(35.4)$ & $48(37.8)$ & $137(35.5)$ & $0.757^{\mathrm{b}}$ \\
\hline \multicolumn{6}{|l|}{ Individual symptoms of FD (n [\%]) } \\
\hline Early satiety & $74(56.5)$ & $76(58.0)$ & $75(59.1)$ & $225(57.8)$ & $0.916^{\mathrm{b}}$ \\
\hline Postprandial fullness & $97(74.0)$ & $98(74.8)$ & $101(79.5)$ & $296(76.1)$ & $0.540^{\mathrm{b}}$ \\
\hline Epigastric pain or soreness & $78(59.5)$ & $68(51.9)$ & $72(56.7)$ & $218(56.0)$ & $0.453^{\mathrm{b}}$ \\
\hline \multicolumn{6}{|l|}{ Subtypes of functional dyspepsia (n [\%]) } \\
\hline PDS & $110(84.0)$ & $114(87.0)$ & $114(89.8)$ & $338(86.9)$ & $0.386^{\mathrm{b}}$ \\
\hline EPS & $75(57.3)$ & $64(48.9)$ & $66(52.0)$ & $205(52.7)$ & $0.388^{\mathrm{b}}$ \\
\hline Overlap of PDS and EPS & $54(41.2)$ & $47(35.9)$ & $53(41.7)$ & $154(39.6)$ & $0.564^{\mathrm{b}}$ \\
\hline
\end{tabular}

${ }^{a}$ Result of Kruskal-Wallis test for comparison between each group.

${ }^{\mathrm{b}}$ Result of Chi-square test for comparison between each group.

FD, functional dyspepsia; PDS, postprandial distress syndrome; EPS, epigastric pain syndrome.

Table 2. Primary Efficacy End-points at 2 and 4 Weeks After Administration

\begin{tabular}{|c|c|c|c|c|}
\hline & $\begin{array}{l}\text { DA-9701 } \\
(\mathrm{n}=131)\end{array}$ & $\begin{array}{l}\text { Pantoprazole } \\
(\mathrm{n}=131)\end{array}$ & $\begin{array}{c}\text { DA-9701 + pantoprazole } \\
(\mathrm{n}=127)\end{array}$ & $P$ \\
\hline \multicolumn{5}{|l|}{ At week 2 (n [\%]) } \\
\hline Improved by binary outcome & $71(55.0)$ & $81(61.8)$ & $68(54.0)$ & 0.382 \\
\hline 5-Likert scale $\geq 2$ & $64(49.6)$ & $70(53.4)$ & $60(47.6)$ & 0.637 \\
\hline \multicolumn{5}{|l|}{ At week 4 (n [\%]) } \\
\hline Improved by binary outcome & $85(65.9)$ & $99(75.6)$ & $88(69.8)$ & 0.227 \\
\hline 5 -Likert scale $\geq 2$ & $78(60.5)$ & $86(65.6)$ & $80(63.5)$ & 0.685 \\
\hline
\end{tabular}

This analysis was conducted in the intention-to-treat set and results were compared using a Chi-square test for comparisons among 3 groups.

symptom improvement at week 2 after administration was achieved in $49.6 \%$ in the DA-9701 group, $53.4 \%$ in the pantoprazole group, and $47.6 \%$ in the DA-9701 + pantoprazole group $(P=0.637$, Table 2). Also symptom improvement measured by binary outcome was significantly achieved in each of the 3 groups, but there were no significant differences among the 3 groups at week 4 (Table 2).

The response rates at week 4 were $69.0 \%$ in the DA-9701 group, $78.0 \%$ in the pantoprazole group and $66.1 \%$ in the DA$9701+$ pantoprazole group, however, there was no statistical difference among 3 groups $(P=0.111)$. The rate of adequate relief, as evidenced by patient diary, was $58.7 \pm 28.1 \%$ in the DA9701 group, $64.6 \pm 26.9 \%$ in the pantoprazole group, and 59.2 $\pm 27.2 \%$ in the DA-9701 + pantoprazole group after 4 weeks of administration, which again was not statistically different among the 3 groups $(P=0.134)$.

\section{Individual Symptom Relief}

Patients in all 3 treatment groups reported significant improvement from the baseline in individual symptoms of FD as assessed by daily diary during treatment. Epigastric pain scores were significantly decreased in the 3 groups at 2-4 weeks after administration in comparison with before administration (-2 week to 0 week) (DA9701 group: $-1.6 \pm 3.4$, pantoprazole group: $-1.3 \pm 2.8, \mathrm{DA}-$ $9701+$ pantoprazole group: $-1.1 \pm 3.5 ; P<0.001$ ) (Table 3 ). The epigastric soreness score, early satiety score, and postprandial fullness score showed statistically significant decrease in each of the 3 groups, but there were no significant differences among the 3 groups. 
Table 3. Changes in Individual and Total Symptom Scores After 4 Weeks of Administration

\begin{tabular}{|c|c|c|c|c|}
\hline Changes of symptom score & $\begin{array}{l}\text { DA-9701 } \\
(\mathrm{n}=115)\end{array}$ & $\begin{array}{l}\text { Pantoprazole } \\
(\mathrm{n}=109)\end{array}$ & $\begin{array}{c}\text { DA-9701 + pantoprazole } \\
(\mathrm{n}=108)\end{array}$ & $P$ \\
\hline $\begin{array}{l}\text { Epigastric pain } \\
\quad P\end{array}$ & $\begin{array}{l}-1.6 \pm 3.4 \\
<0.001^{\mathrm{b}}\end{array}$ & $\begin{array}{l}-1.3 \pm 2.8 \\
<0.001^{\mathrm{b}}\end{array}$ & $\begin{array}{l}-1.1 \pm 3.5 \\
<0.001^{\mathrm{b}}\end{array}$ & $0.169^{\mathrm{a}}$ \\
\hline $\begin{array}{l}\text { Epigastric soreness } \\
\quad P\end{array}$ & $\begin{array}{c}-1.7 \pm 3.1 \\
<0.001^{\mathrm{b}}\end{array}$ & $\begin{array}{c}-1.3 \pm 2.8 \\
<0.001^{\mathrm{b}}\end{array}$ & $\begin{array}{c}-1.2 \pm 3.3 \\
<0.001^{\mathrm{b}}\end{array}$ & $0.848^{\mathrm{a}}$ \\
\hline $\begin{array}{l}\text { Early satiety } \\
\quad P\end{array}$ & $\begin{array}{l}-1.6 \pm 2.7 \\
<0.001^{\mathrm{b}}\end{array}$ & $\begin{array}{l}-1.6 \pm 2.7 \\
<0.001^{\mathrm{b}}\end{array}$ & $\begin{array}{l}-1.5 \pm 2.7 \\
<0.001^{\mathrm{b}}\end{array}$ & $0.805^{\mathrm{a}}$ \\
\hline $\begin{array}{l}\text { Postprandial fullness } \\
\quad P\end{array}$ & $\begin{array}{l}-2.4 \pm 3.1 \\
<0.001^{\mathrm{b}}\end{array}$ & $\begin{array}{l}-2.1 \pm 3.0 \\
<0.001^{\mathrm{b}}\end{array}$ & $\begin{array}{l}-2.1 \pm 3.0 \\
<0.001^{\mathrm{b}}\end{array}$ & $0.325^{\mathrm{a}}$ \\
\hline $\begin{array}{l}\text { Total score } \\
P\end{array}$ & $\begin{array}{l}-7.5 \pm 10.5 \\
<0.001^{\mathrm{b}}\end{array}$ & $\begin{array}{c}-6.3 \pm 10.0 \\
<0.001^{\mathrm{b}}\end{array}$ & $\begin{array}{c}-5.9 \pm 10.2 \\
<0.001^{\mathrm{b}}\end{array}$ & $0.157^{\mathrm{a}}$ \\
\hline
\end{tabular}

${ }^{a}$ Kruskal-Wallis test for comparisons among 3 groups.

${ }^{b}$ Wilcoxon signed rank test for comparison of before/after administration.

This analysis was conducted in per-protocol analysis. Data are presented as mean $\pm \mathrm{SD}$.

Table 4. Changes in Dyspepsia-related Quality of Life After 2 and 4 Weeks of Drug Administration

\begin{tabular}{cccc}
\hline & $\begin{array}{c}\text { DA-9701 } \\
(\mathrm{n}=115)\end{array}$ & $\begin{array}{c}\text { Pantoprazole } \\
(\mathrm{n}=109)\end{array}$ & $\begin{array}{c}\text { DA-9701+ pantoprazole } \\
(\mathrm{n}=108)\end{array}$ \\
\hline Difference in QOL at week 2 & $14.4 \pm 15.9$ & $15.7 \pm 15.7$ & $15.2 \pm 15.8$ \\
$P$ & $<0.001^{\mathrm{b}}$ & $<0.001^{\mathrm{b}}$ & $<0.001^{\mathrm{b}}$ \\
Difference in QOL at week 4 & $20.4 \pm 17.2$ & $19.9 \pm 15.1$ & $19.3 \pm 16.6$ \\
$P$ & $<0.001^{\mathrm{b}}$ & $<0.001^{\mathrm{b}}$ & $<0.001^{\mathrm{b}}$ \\
\hline
\end{tabular}

${ }^{a}$ Kruskal-Wallis test for comparisons among 3 groups.

${ }^{\mathrm{b}}$ Wilcoxon signed rank test for comparison of before/after administration.

QOL, quality of life.

This analysis was conducted in per-protocol analysis. Data are presented as mean \pm SD

\section{Changes in Dyspepsia-specific Quality of Life}

Dyspepsia-related QOL markedly improved in all 3 groups at 4 weeks in comparison with the baseline (QOL change from baseline; DA-9701 group, $20.4 \pm$ 17.2; pantoprazole group, $19.9 \pm$ 15.1; DA-9701 + pantoprazole group, $19.3 \pm 16.6 ; P<0.001$ ). There was also significant improvement in the QOL 2 weeks after administration in all 3 groups; however, there were no differences in the QOL among the 3 groups at 2 and 4 weeks after administration (Table 4).

\section{Symptomatic Relief According to the Subtypes of Functional Dyspepsia}

The proportion of symptomatic improvement in PDS at 4 weeks was $60.4 \%$ in the DA-9701 group, $66.7 \%$ in the pantoprazole group, and $61.2 \%$ in the DA-9701 + pantoprazole group using the 5-Likert scale. Improvement in EPS was $70.0 \%$ in the DA-9701 group, $57.1 \%$ in the pantoprazole group and $41.7 \%$ in the DA-9701 + pantoprazole group. The symptomatic improvement rate of subjects with overlap in the EPS and PDS groups was $66.0 \%$ in the DA-9701 group, $73.7 \%$ in the pantoprazole group, and $70.2 \%$ in the DA-9701 + pantoprazole group. In FD subtypes, there were no statistically significant differences among the treatment groups (Table 5).

\section{Symptomatic Relief According to the Helicobacter pylori Status}

A total of $35.5 \%$ of patients (137/389) were H. pylori-positive. Among the $H$. pylori-positive group, the proportion of symptomatic improvement using the 5-Likert scale was significantly higher in the pantoprazole alone or combination therapy group compared with the DA-9701 alone group (Chi-square test among the 3 groups, $P=0.023$; Bonferroni-Holm's step-down between DA-9701 and pantoprazole, $P=0.025$ ) (Fig. 2). However, there were no differences in the symptom improvement rate among the 3 groups in the $H$. pylori-negative population. 
Table 5. Symptom Improvement Rates According to Functional Dyspepsia Subtype

\begin{tabular}{|c|c|c|c|c|}
\hline & $\begin{array}{l}\text { DA-9701 } \\
(\mathrm{n}=115)\end{array}$ & $\begin{array}{l}\text { Pantoprazole } \\
(\mathrm{n}=109)\end{array}$ & $\begin{array}{c}\text { DA-9701 + pantoprazole } \\
(\mathrm{n}=108)\end{array}$ & $P$ \\
\hline PDS only & $(n=48)$ & $(\mathrm{n}=57)$ & $(n=49)$ & \\
\hline Improved by binary outcome (n [\%]) & $34(70.8)$ & $43(75.4)$ & $34(69.4)$ & 0.766 \\
\hline 5-Likert scale $\geq 2(\mathrm{n}[\%])$ & $29(60.4)$ & $38(66.7)$ & $30(61.2)$ & 0.766 \\
\hline EPS only & $(n=20)$ & $(n=14)$ & $(\mathrm{n}=12)$ & \\
\hline Improved by binary outcome (n [\%]) & $11(55.0)$ & $11(78.6)$ & $7(58.3)$ & 0.152 \\
\hline 5-Likert scale $\geq 2(\mathrm{n}[\%])$ & $14(70.0)$ & $8(57.1)$ & $5(41.7)$ & 0.865 \\
\hline PDS + EPS & $(n=47)$ & $(\mathrm{n}=38)$ & $(n=47)$ & \\
\hline Improved by binary outcome (n [\%]) & $34(72.3)$ & $32(84.2)$ & $35(74.5)$ & 0.402 \\
\hline 5 -Likert scale $\geq 2(\mathrm{n}[\%])$ & $31(66.0)$ & $28(73.7)$ & $33(70.2)$ & 0.743 \\
\hline
\end{tabular}

PDS, postprandial distress syndrome; EPS, epigastric pain syndrome.

This analysis was conducted in per-protocol analysis. The Chi-square test was used for comparisons among 3 groups. $P<0.05$; the data are mutually exclusive. Data are presented as n $[\%]$.

A

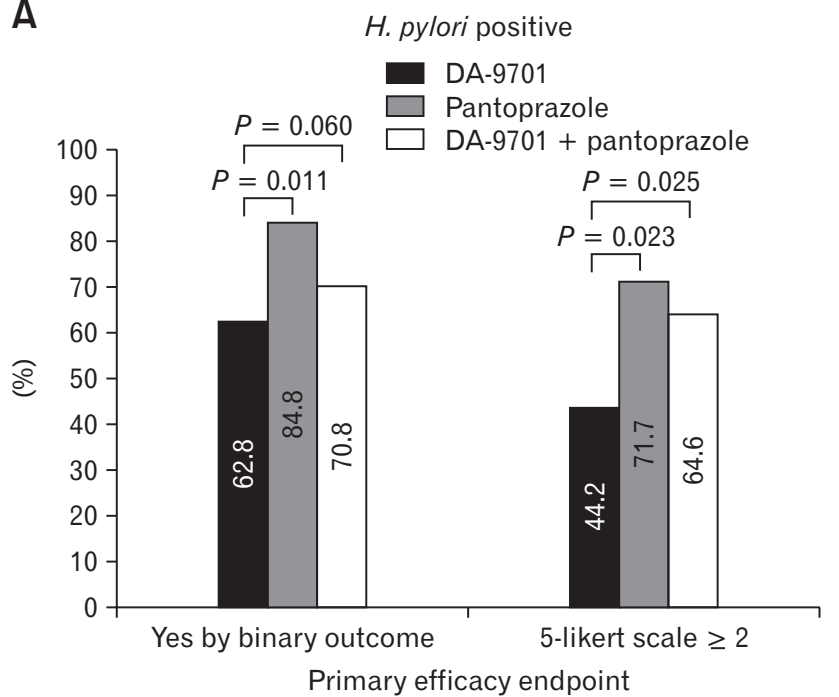

B

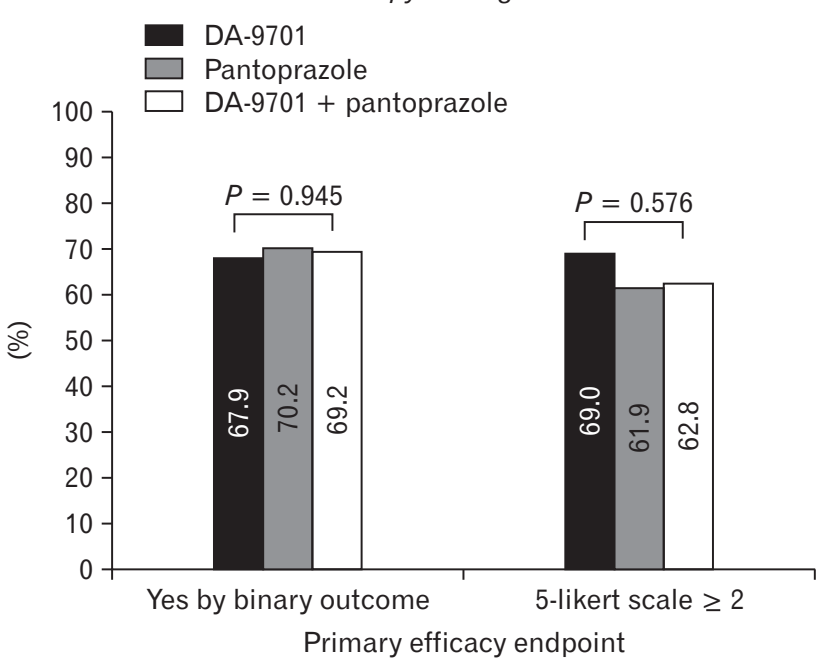

Figure 2. Symptomatic relief according to the Helicobacter pylori status. In the H. pylori positive group, the symptom improvement rate was significantly higher in the pantoprazole and DA-9701 + pantroprazole group than that in DA-9701 group. However, this difference was not detected in the H. pylori-negative group. The Chi-square test was performed among the 3 groups and Bonferroni-Holm's step-down was used for comparison within each group.

\section{Safety Assessment}

Treatment-emergent adverse events were reported by $17.8 \%$ in the DA-9701 group, $16.8 \%$ in the pantoprazole group, and $11.9 \%$ in the DA-9701 + pantoprazole group (Table 6). The most frequently reported adverse events were nausea, diarrhea, and vomiting of mild severity. There were no deaths during the study and no clinically significant cardiovascular events. A serious adverse event was reported by 1 patient in the DA-9701 + pantoprazole group who was admitted because of acute cholecystitis. In that case, we did not find any causality associated with the drug.

\section{Discussion}

Treatment of FD remains a challenge. A meta-analysis reported that prokinetics, such as cisapride, were the most effective drug in dyspepsia with dichotomous outcome measurement (relative risk reduction $33 \%$, 95\% CI 18-45\%). ${ }^{5}$ However, the studies were highly heterogeneous, and cisapride has been withdrawn from the 
Table 6. Treatment-emergent Adverse Events

\begin{tabular}{|c|c|c|c|}
\hline & $\begin{array}{l}\text { DA-9701 } \\
(\mathrm{n}=129)\end{array}$ & $\begin{array}{l}\text { Pantoprazole } \\
(\mathrm{n}=131)\end{array}$ & $\begin{array}{c}\text { DA-9701 + pantoprazole } \\
(\mathrm{n}=126)\end{array}$ \\
\hline All treatment-emergent adverse events & $23(17.8)$ & $22(16.8)$ & $15(11.9)$ \\
\hline Nausea & $4(3.1)$ & $2(1.5)$ & $1(0.8)$ \\
\hline Diarrhea & $3(2.3)$ & $1(0.8)$ & $1(0.8)$ \\
\hline Abdominal pain & $2(1.6)$ & $0(0.0)$ & $3(2.4)$ \\
\hline Constipation & $3(2.3)$ & $1(0.8)$ & $0(0.0)$ \\
\hline Vomiting & $4(3.1)$ & $0(0.0)$ & $0(0.0)$ \\
\hline Abdominal distension & $1(0.8)$ & $1(0.8)$ & $0(0.0)$ \\
\hline Dizziness & $2(1.6)$ & $4(3.1)$ & $2(1.6)$ \\
\hline Headache & $1(0.8)$ & $2(1.5)$ & $1(0.8)$ \\
\hline Pruritus & $1(0.8)$ & $3(2.3)$ & $0(0.0)$ \\
\hline Urticaria & $0(0.0)$ & $2(1.5)$ & $1(0.8)$ \\
\hline
\end{tabular}

This analysis was conducted in the safety set. Treatment-emergent adverse event is defined as adverse events which appear after drug administration or adverse events which exacerbate symptoms after administration compared to before administration; the data are not mutually exclusive. Data are presented as $\mathrm{n}$ [\%].

market because of cardiac toxicity. Despite early promising results, newly developed prokinetics did not show the definitive symptom improvement in FD. ${ }^{14-16}$

DA-9701 is a newly developed prokinetic agent obtained from the vegetal extracts that improves gastric emptying with visceral analgesic effects. ${ }^{10-12}$ The present randomized controlled study showed that DA-9701 was not inferior to 40-mg pantoprazole. The combination of DA-9701 and pantoprazole did not have an additive effect on the improvement of FD symptoms compared with monotherapy of DA-9701 or pantoprazole, as measured by the primary and secondary study end-points. In the present study, we excluded subjects with dyspepsia accompanied with GERD to avoid the misclassification bias in the efficacy of PPIs in GERD patients. DA-9701 produced highly effective relief for all symptom endpoints, and about $60 \%$ of patients in all 3 treatment groups achieved resolution of dyspeptic symptoms at week 4 , and about $50 \%$ of patients achieved symptom relief within 2 weeks. These results are compatible with a previous study. Hsu et $\mathrm{al}^{8}$ reported similar symptom improvement ( $\sim 50 \%$ ) with 30-mg lansoprazole and mosapride in 329 patients with FD.

PPIs are one of the most extensively investigated drugs in FD. Although mixed results have been observed in individual studies, meta-analysis revealed that PPIs were significantly more effective than placebo for treating patients with $\mathrm{FD}$, with a $10.3 \%$ reduction in relative risk of dyspeptic symptoms. ${ }^{17}$ In a large randomized controlled study $(\mathrm{n}=1262)$, omeprazole was modestly superior to placebo in a dose-dependent manner. ${ }^{18}$ In this study, complete symptom relief was achieved in patients with ulcer-like and reflux- like dyspepsia, but no benefit was seen with dysmotility-like dyspepsia. Modulation of gastric acid secretion is a possible explanation for efficacy of PPIs in FD. The majority of FD patients have normal acid secretion, ${ }^{19}$ however, acid suppressive therapy provides symptomatic relief. In FD patients, duodenal acid infusion provoked nausea, but not in healthy volunteers and duodenal acidification decreased the gastric accommodation by duodeno-gastric reflex. ${ }^{20}$ Also 24-hour ambulatory duodenal $\mathrm{pH}$ monitoring demonstrated the increased duodenal acid exposure in FD. ${ }^{20}$ These studies suggest that the acid-hypersensitivity in duodenum might explain the efficacy of PPIs in subset of FD patients.

Interestingly, the therapeutic gain of PPIs is changed based on $H$. pylori infection. Blum et $\mathrm{al}^{21}$ reported that the efficacy of omeprazole was only evident in the $H$. pylori-positive subgroups. Thus, the anti-secretory effect of PPIs might be enhanced in $H$. pylori infection. These results were reproduced in the present study. In the $H$. pylori-positive group, pantoprazole was more effective than DA-9701, but this difference was not detected in the $H$. pylori-negative group. The previous study reported that a disturbance in gastrin releasing peptide-stimulated acid secretion was detected in $50 \%$ of patients with $\mathrm{FD}$, and the increased gastrin releasing peptide-relating acid secretion was frequently found in $H$. pyloriinfected patients with FD compared to $H$. pylori-positive healthy controls. $^{22}$

There are few studies directly comparing the efficacy of PPIs and prokinetics in Asia. Hsu et al. $^{8}$ reported that the efficacy of PPI was similar to prokinetics in patients with FD according to the Rome III criteria after 2 weeks of treatment. In another study of 
patients with $H$. pylori-negative uninvestigated dyspepsia, PPI was more effective compared with $\mathrm{H}_{2}$ receptor antagonist or prokinetics. With 4 weeks of drug treatment, sufficient symptom relief was reported in $66.9 \%$ of the omeprazole group, $41.0 \%$ of the famotidine group, $36.3 \%$ of the mosapride group, and $32.3 \%$ of the teprenon group. ${ }^{23}$

The co-administration of PPI and prokinetics is commonly prescribed for patients with $\mathrm{FD}$ and is frequently recommended by clinical guidelines, although the efficacy has been questioned. The present study documented that combining DA-9701 with PPI provided no additional amelioration of dyspeptic symptoms compared with PPI or prokinetics alone. This finding might be the first report of the efficacy of prokinetic and PPI combination therapy in terms of direct comparison with prokinetic or PPI monotherapy. Limited studies have been performed in patients with non-erosive reflux disease combined with dyspeptic symptoms. ${ }^{24}$ In this study, mosapride and omeprazole combination therapy did not improve reflux symptom or esophageal secondary peristalsis. In another study in Japan, combination with acotiamide and esomeprazole was effective in 18 of $23 \mathrm{FD}$ patients (78\%) refractory to PPI monotherapy. However, the sample size was small and there was no control arm in this study. ${ }^{25}$

We observed that the response rate to mono- or combination therapy of DA-9701 or PPIs was not different between the subtypes of FD according to the ROME III criteria. This finding is consistent with the previous studies. ${ }^{9,26}$ Another previous study reported that the complete symptom relief was achieved similarly by PPIs among the FD subgroups; ie, ulcer-like, dysmotility-like, reflux-like, and unspecified dyspepsia. ${ }^{27}$ Further clinical investigations are urgently needed to assess the utility of FD subgroups defined by the Rome III criteria in clinical study and practice.

This study had several limitations. The population did not include an adequate number of $H$. pylori-positive patients to prove efficacy according to FD subtypes, there was an insufficient duration to assess the long-term efficacy, and an insufficient validation of the response to understand the clinical significance. Secondly, we did not perform a gastric physiologic study such as the gastric emptying test. Improving gastric emptying or accommodation seems to be an attractive therapeutic target in patients FD. In a recent study with DA-9701 in healthy volunteers, pre-treatment with DA-9701 significantly increased gastric emptying. ${ }^{28}$ DA-9701 enhances gastric emptying via $\mathrm{D}_{2}$ antagonism and $5-\mathrm{HT}_{4}$ agonism. ${ }^{29}$ Thirdly, another limitation was the lack of a placebo arm in this study. In Asia, there is some controversy over PPIs' efficacy in FD because a few available studies reported heterogeneity in methodologies and results with a small sample size. ${ }^{30}$

In conclusion, treatment with DA-9701 for up to 4 weeks significantly improved global and individual symptoms and increased dyspepsia-specific QOL compared to before treatment in patients with FD. The efficacy of DA-9701 monotherapy was comparable with pantoprazole, and there was no additive effect with combination of DA-9701 and pantoprazole in patients with FD.

Acknowlegements: This study was sponsored by Donga-A ST, Seoul, Korea. The authors are solely responsible for the contents, and the content does not necessarily represent the official views of the Donga-A ST.

\section{Financial support: None.}

\section{Conflicts of interest: None.}

Author contributions: Kwang Jae Lee: study design, implementation, data acquisition, and critical revision of manuscript; Hye-Kyung Jung: study design, implementation, data analysis, and drafting of manuscript; and Myung-Gyu Choi, Hyojin Park, Joon Seong Lee, Poong-Lyul Rhee, Nayoung Kim, Kyung Sik Park, Suck Chei Choi, Oh Young Lee, Kyu Chan Huh, Geun Am Song, Sujin Hong, Chong Il Sohn, Hwoon-Yong Jung, Yong Chan Lee, Jong Sun Ryu, Sam Ryong Jee, and Joong Goo Kwon: implementation and data acquisition.

Trial registration: ClinicalTrials.gov Identifier: NCT01817465.

\section{References}

1. Knill-Jones RP. Geographical differences in the prevalence of dyspepsia. Scand J Gastroenterol Suppl 1991;182:17-24.

2. Tack J, Talley NJ, Camilleri M, et al. Functional gastroduodenal disorders. Gastroenterology 2006;130:1466-1479.

3. Tack J, Bisschops R, Sarnelli G. Pathophysiology and treatment of functional dyspepsia. Gastroenterology 2004;127:1239-1255.

4. Choi MG, Jung HK. Health related quality of life in functional gastrointestinal disorders in Asia. J Neurogastroenterol Motil 2011;17:245-251.

5. Moayyedi P, Soo S, Deeks J, Delaney B, Innes M, Forman D. Pharmacological interventions for non-ulcer dyspepsia. Cochrane Database Syst Rev 2006:(4):CD001960.

6. Corleto VD, Festa S, Di Giulio E, Annibale B. Proton pump inhibitor therapy and potential long-term harm. Curr Opin Endocrinol Diabetes Obes 2014;21:3-8.

7. Talley NJ, Vakil N; Practice Parameters Committee of the American College of Gatroenterology. Guidelines for the management of dyspepsia. Am J Gastroenterol 2005;100:2324-2337. 
8. Hsu YC, Liou JM, Yang TH, et al. Proton pump inhibitor versus prokinetic therapy in patients with functional dyspepsia: is therapeutic response predicted by Rome III subgroups? J Gastroenterol 2011;46:183-190.

9. Lee TH, Choi JJ, Kim DH, et al. Gastroprokinetic effects of DA-9701, a new prokinetic agent formulated with Pharbitis Semen and Corydalis Tuber. Phytomedicine 2008; 15:836-843.

10. Kim ER, Min BH, Lee SO, Lee TH, Son M, Rhee PL. Effects of DA-9701, a novel prokinetic agent, on gastric accommodation in conscious dogs. J Gastroenterol Hepatol 2012;27:766-772.

11. Kim ER, Min BH, Lee TH, Son M, Rhee PL. Effect of DA-9701 on colorectal distension-induced visceral hypersensitivity in a rat model. Gut Liver 2014;8:388-393.

12. Lee TH, Son M, Kim SY. Effects of corydaline from Corydalis tuber on gastric motor function in an animal model. Biol Pharm Bull 2010;33: 958-962.

13. Cho YK, Choi MG, Kim SH et al. [The effect of mosapride on quality of life in functional dyspepsia.] Korean J Gastroenterol 2004;43:160-167. [Korean]

14. Holtmann G, Talley NJ, Liebregts T, Adam B, Parow C. A placebo-controlled trial of itopride in functional dyspepsia. N Engl J Med 2006;354: 832-840.

15. Talley NJ, Tack J, Ptak T, Gupta R, Giguère M. Itopride in functional dyspepsia: results of two phase III multicentre, randomised, doubleblind, placebo-controlled trials. Gut 2008;57:740-746.

16. Quigley EM. Prokinetics in the management of functional gastrointestinal disorders. J Neurogastroenterol Motil 2015;21:330-336.

17. Wang WH, Huang JQ, Zheng GF, et al. Effects of proton-pump inhibitors on functional dyspepsia: a meta-analysis of randomized placebocontrolled trials. Clin Gastroenterol Hepatol 2007;5:178-185.

18. Talley NJ, Meineche-Schmidt V, Paré P, et al. Efficacy of omeprazole in functional dyspepsia: double-blind, randomized, placebo-controlled trials (the Bond and Opera studies). Aliment Pharmacol Ther 1998;12:10551065 .

19. Nyren O, Adami HO, Gustavsson S, Lindgren PG, Löö L, Nyberg A. The "epigastric distress syndrome". A possible disease entity identified by history and endoscopy in patients with nonulcer dyspepsia. J Clin Gastroenterol 1987;9:303-309.
20. Lee KJ and Tack J. Duodenal implications in the pathophysiology of functional dyspepsia. J Neurogastroenterol Motil 2010;16:251-257.

21. Blum AL, Arnold R, Stolte M, Fischer M, Koelz HR. Short course acid suppressive treatment for patients with functional dyspepsia: results depend on Helicobacter pylori status. The Frosch Study Group. Gut 2000; 47:473-480.

22. el-Omar E, Penman I, Ardill JE, McColl KE. A substantial proportion of non-ulcer dyspepsia patients have the same abnormality of acid secretion as duodenal ulcer patients. Gut 1995;36:534-538.

23. Sakurai K, Nagahara A, Inoue K, et al. Efficacy of omeprazole, famotidine, mosapride and teprenone in patients with upper gastrointestinal symptoms: an omeprazole-controlled randomized study (J-FOCUS). BMC Gastroenterol 2012;12:42.

24. Futagami S, Iwakiri K, Shindo T, et al. The prokinetic effect of mosapride citrate combined with omeprazole therapy improves clinical symptoms and gastric emptying in PPI-resistant NERD patients with delayed gastric emptying. J Gastroenterol 2010;45:413-421.

25. Mayanagi S, Kishino M, Kitagawa Y, Sunamura M. Efficacy of acotiamide in combination with esomeprazole for functional dyspepsia refractory to proton-pump inhibitor monotherapy. Tohoku J Exp Med. 2014; 234:237-240.

26. Choi MG, Rhee PR, Park H, et al. Randomized, controlled, multicenter trial: comparing the safety and efficacy of DA-9701 and itopride hydrochloride in patients with functional dyspepsia. J Neurogastroenterol Motil 2015;21:414-422.

27. Wong WM, Wong BC, Hung WK, et al. Double blind, randomised, placebo controlled study of four weeks of lansoprazole for the treatment of functional dyspepsia in Chinese patients. Gut 2002;51:502-506.

28. Min YW, Min BH, Kim S, Choi D, Rhee PL. Effect of DA-9701 on gastric motor function assessed by magnetic resonance imaging in healthy volunteers: A randomized, double-blind, placebo-controlled trial. PLoS One 2015;10:e0138927.

29. Kwon YS, Son M. DA-9701: a new multi-acting drug for the treatment of functional dyspepsia. Biomol Ther (Seoul) 2013;21:181-189.

30. Wang WH, Huang JQ, Zheng GF, et al. Effects of proton-pump inhibitors on functional dyspepsia: a meta-analysis of randomized placebocontrolled trials. Clin Gastroenterol Hepatol 2007;5;178-185. 